\title{
ELS CONCEPTES DE LA MORAL I L'EDUCACIÓ
}

\author{
Ramon Cortada Corominas \\ (Universitat de Girona)
}

Descartes, Rousseau i Kant reducixen l'home a un nivell de naturalesa abstracta intel-ligible, per efectes exteriors a l'home: reforma del mètode, la qual produirà "la més elevada i perfecta moral" - Descartes-:' reforma de la societat, la qual retornard a l'home la seva bondat primitiva - Rousseau-; reforma de la filosofia $i$ de la raó que assegurarà el "regnat dels fins" - Kant-. Segons Kant, la moral ha d'aplicar-se "a tot ésser racional en general", $i$ totes les lleis morals han de ser deduïdes "del concepte universal d'un ésser racional en general".

Cal dir que és per l'experiència —-psicològica, sociològica, històrica一, no pas "a priori", per on ens formem el concepte d'un ésser recional. A més, la moral no té per objecte el racional en general, sinó el racional humà. L'experiència de la qual parteix el moralista en definir la naturalesa moral de l'home no és la d'una naturalesa pura, sinó la de l'home existencialment posat. Sòcrates fa del "coneix-te a tu mateix" el fonament de la moral. L'experiència ens introdueix en el coneixement de l'home. Els deures ho són en funció de les condicions en les quals es desenvolupa la seva activitat.

Els conceptes de la moral són alhora empirics — pel seu origen-i racionals — per la seva forma-. Però el seu origen empiric no afecta la seva universalitat ni la seva necessitat, i tampoc el seu caràcter racional —o metafisic - no exclou el seu valor experimental. Per a Aristòtil, l'experiència moral és la d'una raó aplicada a allò concret, i mitjançant l'abstracció formal -condicionada per l'estudi dels costums, el dret, les situacions socio-politiques, etc...-. es capten essències i naturaleses universals. ${ }^{2}$ En canvi, Kant creu que la filosofia moral "aplicada a l'home no s'aprofita en res del coneixement d'allò que és -antropologia-" i cal que sigui enterament "a priori". ${ }^{3}$

$\mathrm{Ni}$ els principis ni els conceptes de la moral —nocions de bé i de mal, deures, Heis, virtuts, etc...-, tot i que s'abstreuen de l'experiència i s'orienten al concret, són de naturalesa empirioldgica. Pels seus continguts i per voler sistematitzar el conjunt de deures i drets referint-los, mitjançant connexions necessàries, als seus fins universals, la moral és, en aquest pla de les "ráons de l'ésser", ontològica,"

L'ètica és la formulació, d'acord amb les lleis del judici, d'allò que ens és donat en l'esfera del coneixement moral. $A$ Kant, el deure - "l'laver de ser" precedeix el valor; a Scheler, el valor precedeix el deure - "I'haver de ser", i considera que la conducta moral està formada pel coneixement intuittiu d'un valor, amb el seu propi contingut "a priori" $\mathrm{i}$ la seva pròpia evidència. El positivisme confon la valoració $\mathrm{i}$ el valor - la nostra visió dels valors i la corresponent reacció amb els valors mateixos-. Per als idealistes, una valoració is quelcom diferent del valor mateix - les estimacions són variables. relatives, en permanent canvi; els valors en si són eterns $\mathrm{i}$ immutables-. Aquesta teoria que arrela a Plató is desenvolupa. da per Scheler.

I I DESCARTES: Préface des Principes de la Philosophie.

2 ARISTÓTIL, Ética a Nic., I, c. VIII, 1096 a 2I-b-9; c. III, 1094 b, 27-1095 a 11.

3 KANT (1984): Fonamentacio metofisica dels cosfums, -2a seccio-. Laia.

4 JOLIVERT, R. (1966): Moral, Carlos Lohlé, pp. 14-17; 22-26; 34-37. 
Nosaltres pensem que els valors tenen consistència en el nostre esperit, però tenen un cert fonament en el món. Els valors estan fonamentats en la relació entre l'home $\mathrm{j}$ les coses. ${ }^{5}$ Els valors $i$ el coneixement estan associats en l'acció $i$ en el discurs. ${ }^{\circ} \mathrm{La}$ intersecció de l'individualsubjectiu amb el supraindividual objectiu genera la personalitat; "personalitzar l'individu és l'objecte de la formació"7 Si educar és "optimitzar", segons Sanvisens un sistema de regulació s'optimitza "quan la diferència entre el valor real de la seva acció electiva i el valor ideal del seu objectiu o nivell d'actuació tendeix a desaparcixer -tendeix a zero-".8 La qualitat de l'educació ve determinada per la dignitat, la profunditat i l'extensió dels valors que hagim estat capaços de suscitar i realitzar. ${ }^{9}$

Les ciències normatives pretenen definir les lleis a les quals cal que es conformi l'activitat humana. Els positivistes volen integrar aquestes ciències en el dret comú de les ciències de la naturalesa. Aixè és el que signifiquen les definicions de la moral com a "fisica dels costums" o "biologia dels costums" - A. Comte, Stuart Mill, Spencer- o també com a "art o tècnica sociológica" - Durkheim, Lévy Bruhł- ${ }^{10}$ Des d'aquest punt de vista, la norma només podrà induir-se de l'experiència interpretada cientificament. Es tracta d'una tesis comuna a totes les doctrines positivistes, tot $\mathrm{j}$ que entre elles hi ha diterències observables. Aixi, a Comte, Stuart Mill i Spencer, ès admissible des del punt de vista biològic i el sociològic, l'existència d'un tipus de perfecció humana, la qual s'ha de realitzar en el darrer estadi de l'evolució social -Loi de trois états-; i, per la seva part, Durkheim rebutja categòricament aquesta concepció, ja que la ciència ha d'atenir-se als fets, i codificar, en certa manera, allò que és admés pel medi social; els preceptes no són altra cosa que l'expressió de la coacció exercida per la societat sobre l'individu.

Si Comte constitueix la sociologia en ciènoia positiva - -la primera condició d'una ciència social és l'observació dels fets socials"ll_, serả Durkheim qui tractarà de donar més rigor a la noció d'una sociologia positiva, convertint-la en una ciència estrictament autónoma, amb un objecte formal ben definit, i amb una idea general del mètode similar a la de les ciències de la naturalesa. Durkheim és qui obre el pas a la sociologia analitica. Considera els fets socials independentment dels prejudicis subjectius i de les voluntats individuals; ${ }^{12}$ constitueix el principi d'una nova època en la sociologia, la qual desconeix les tradicionals controvèrsies internes de tipus ideològic. ${ }^{13}$ Per a Durkheim la moral $i$ el dret estan fets per a la societat i, per tant. per

5 Vid. FRONDIZI, R. (1972): ¿Qués son los valores? FCE. pp. 141-233.

6 MONOD, J. (1975): El azar y la necesidad. Ensiyo sobre la filosofia natural de la biologia modema, Barral Ed., pp. 186-189.

7 MANTOVANI, J. (1968): Educación y plenikud humana, Ed. Ateneo, p. 76.

8 SANVICENS. A. (1984): Cibernética do lo humano, Ed. Oikos-Tau, p. 209.

9 MARIN IBÁÑEZ, R.: "los valores, fundamento de la educacio", en Castillejo, J.L. i altres (I985): Teoria de la soducación, Ed. Anaya, pp. 65 ss.

10 Comte deia: "La filosofia positivista representa els fenómens socials com a modificables segons les indicacions racionals de la ciéncia. Aquella es reserva la direcció intel.lectual d'aquesta intervenció, els limits de la qual fixa ella mateixa"-cours da Philosophie Positive, lliçó 48. Paris, Jlermann, 1975.

II VID COMTE, A.: Cours da pliil. positive, (lliçons 48-52).

12 DURKHEIM, E.: Règles de la méthode sociologiqus, Ila ed., pp. 20.5.11.

13 GARMENDIA, J.A. (1971): E. Durklıeim: División del trabajo social y anomia. - Eficiencias y deficiencias del análisis estructural funcional-. Resumen tesis doctoral, p. 11.

L'obra metodologica de Max Weber té el mèrit d'luver distingit entre la sociologia $\mathrm{j}$ les altres disciplines antropologiques $\mathrm{j}$, en particular, historiografiques. Reconeix l'objecte de la sociologia en les uniformitats de l'actitud humana en tant que són accesibles a la comprenció - Uber einige Kategorien der verstehenden Soziologie, 1913-; el d'haver establert una distinció precisa entre investigació cmpiriça, d'una part, $i$ les valoracions practi- 
ella. ${ }^{14}$ En aquesta linia de pensament, les idees, el llenguatge, la cultura, etc. tenen un origen purament social, i la Sociologia és l'única ciència pròpiament humana, en la qual la resta de les ciències hi han de trobar les seves respectives materries $i$ orientació. ${ }^{15} \mathrm{El}$ sociologisme postula la "consciència col.lectiva", la qual ho és en cada moment dels pobles, com a font i regle de l'estat social enter i, en consequència, de les formes juridiques que l'expressen. Amb això, queda eliminada gratuïtament tota moral personal $i$ interpersonal $i$ se suprimeix pura $i$ simplement el fet moral d'una responsabilitat personal. Per a Natorp, Bergemann, Kerchensteiner, Durkheim o Dewey, l'educació és integrament social, en els seus agents, en el seu fi $i$ en els seus mitjans. ${ }^{16}$

Si bé es cert que no pot haver-hi un coneixement de l'educació realista sense una referència a la sociologia, creiem que no es pot pensar tota l'educació des de la sociologia, perquè la sociologia no esgota el camp de l'educació. Tant la Pedagogia Social com la Sociologia de l'Educació fan aportacions valuoses als aspectes socials de l'educacio. La primera en l'ordre tedric i ideològic de l'educació; la segona, en l'ordre de les qủestions empiriques i fàctiques del fenomen social de l'educació. Tot i que tenen una naturalesa distinta, tenen afinitats $i$ punts de contacte. ${ }^{17}$ La Pedagogia Social, en sentit estricte, té un caricter ınés aviat tecnicopedagògic $\mathbf{i}$ normatiu, la Sociologia de l'Educació, en sentit estricte, el té més aviat empiricopositiu. Les dues branques "poden conjugar-se i complementar-se, i s'auxilien en el seu desenvolupament i aplicació. ${ }^{18}$ La Pedagogia Social necessita partir de la realitat socioeducativa per a precisar el seu camp bàsicamet pedagògic. La Sociologia de l'Educació necessita de la investigació pedagògica per a conèixer el sentit de la seva investigació empirica. D’aquesta manera, la investigació amb fins nomatius i la investigació amb fins empírics es complementen, coordinant els seus objectius. Pedagogia i Sociologia conserven aixi la seva independencia respectiva, la seva importància fonamental com a estudis humans; "s'estableix alhora una relació biunivoca entre els seus respeclius dominis, l'interès $i$ aplicació de la qual són considerales".19

La dimensió normativa de la pedagogia en el pla racional és acceptada per la majoria dels autors. L'enunernció dels possibles rnètodes varia segons els diferents criteris sistemàtics. El principi ordenador més satisfactori el proporcionen les lormes de coneixement humà. ${ }^{20} \mathrm{Hi}$ ha,

ques, ètiques i metafisiques, de l"altra - Der Sinn der Welfreiheit der soziologisclen und okunomischen Wissenschaften, 1917-; i el de l'exigència, que es desprén de la seva obra, de la investigació tmpirica particular. ta qual només pot determinar les uniformitats d'actitud que constitueixen l'objecte propi de la sociologia. Aquests tres punts s'lan mantingut en l'ulterior desenvolupament de la sociologia contemporánia.

14 DURKJIEIM, E. (19I5): L'education morale, Paris, p. $136 \mathrm{~s}$.

15 QUINTANA, J.M. (1976): "Pedagogia Social y Sociologia de la Educación. ANálisis comparativo" (1), en Perspectivas Pedagogicas, ก. 37.38, p. 164.

16 El primer que empra el terme Pedagogia Social és Natorp-1899- amb un significat que no li és propi. sinó que correspon al que podriem anomenar pedagogia sociológica - també sociologista o sociologisme pedagógic. Natorp és explicit quan diu: "ein el meu article: "pedagogia social", del Manual Enciclopèdic de Pedagogia de Rein, aixi com les discussions amb Truper - Deutsclue Schule, VI, 1902, p. 82- i Edelheim -archiv ar Soziale Gesetzgebung, XVl1, 1902, p. 545-, he diferenciat la interpretació monistica - desenvolupada en la meva obrade la dualistica (...). No té sentit la separació extema d'una pedagogia individual i una pedagogia social". Vid Hovre, Fr. de (1932): Ensajo de Filosolīa Pedagógica, Ed. "Razón y Fe", pp. 95-145.

17 SANVICENS, A. (1969): "Constantes y coincidencias pedagógico-suciales en ta evolución cultural earopea" - Separata de: Las constantes de Europa, VI Semana Intemacianal de Estudios Sociales-, Instituto de Ciencias Sociales, [3arcelona, pp. 493.495.511-518.

18 Ibidem.

19 Ibidem.

20 MÄRZ, Fritz (1968): Introducción a la Pedagogia. Ed. Iterder, p. 34. Vid. Gil, F. (1991): "Sobre la possibilidad de un conocimiento autónomo de la educación y su aplicación a limalidades educativas". En "Teoria de la Educación. Vol. III, p. 113-125. 
d'una banda, els problemes relatius als fins $i$, d'una altra banda, els problenes relatius als mitjans. El pedagog primer determina què cal fer, després es qüestiona com ho ha de fer. Hi ha, per tant, una prioritat de la pedagogia teleològica, a la qual està subordinada la tecnologia educaliva - lècnica d'investigació: investigació objectiva dels millors mitjans per aconseguir el fij; $i$ tècnica de l'cducació: dur a la pràctica aquests mitjans. ${ }^{2 I}$ L'explicació teleològica dels fenòmens educatius és exclusiva de l'explicació racional en relació a la consideració dels valors. I el punt de fonamentació de l'especulació deductiva està constituït, en el camp propi de le pedagogia, per les definicions dels conceptes bàsics. Aquests conceptes bàsics poden ser principis particulars de l'educació —que són el fonament per emprar el mètode racional-, o bé principis radicats en altres ciències -que contribueixen a l'explicació de la pedagogia- "explicant eficientment o teleològicament els fenòmens educatius".22 Caldrà, doncs, plantejar-se el problema de la utilització metodològica d'aquests principis, procedint, en primer lloc, a l'anàlisi dels conceptes fonamentals per explicar les notes implicades en les idees pedagògiques. La primera funció del raonament deductiu surà la justificació teleològica de la teoria de l'educació; la segona funció serà d'ordre pràctic —deducció racional de les nomes d'activitat educativa - d'acord amb els fins de l'educació acceptats, tot tenint present que les construcions teòriques que es realitzin tindran necessitat d'una doble demostració: especulativa i experimental; és el retrobament de l'ordre empiric amb l'ideal en el terreny pedagògic. ${ }^{23}$

Es fa palesa la connexió entre filosofia i educació. Levèque i Best lan considerat que una teoria de l'educació constitueix el problema filosòfic per excel.lència, i es defineix cada gran filosofia com a "paideia".24 Altres com Dilthey, han considerat la pedagogia com la culminació de la filosofia, perquè aquesta pren sentit quan informa la praxis humana. A Descartes, el mateix dret a pensar des de la pròpia raó és principi de pedagogia moral i motor de la seva filosolia.

\footnotetext{
21 PLANCHARD, E. (1969): Pedagogia conteinporinea. Ed. Rialp, 5a ed. pp. 44 ss.

22 GARCIA HOZ, V. (1981): Principios de P'edagogia Sistemálica, Ed. Rialp, 7a ed., pp. 53 ss.

23 Jbidem pp. $61 \mathrm{~s}$.

24 LÉVÉQUE, R. - BEST. F. (1971): Razones para hablar de filosofia de la educación. Ed. Oikos-Tau.
} 